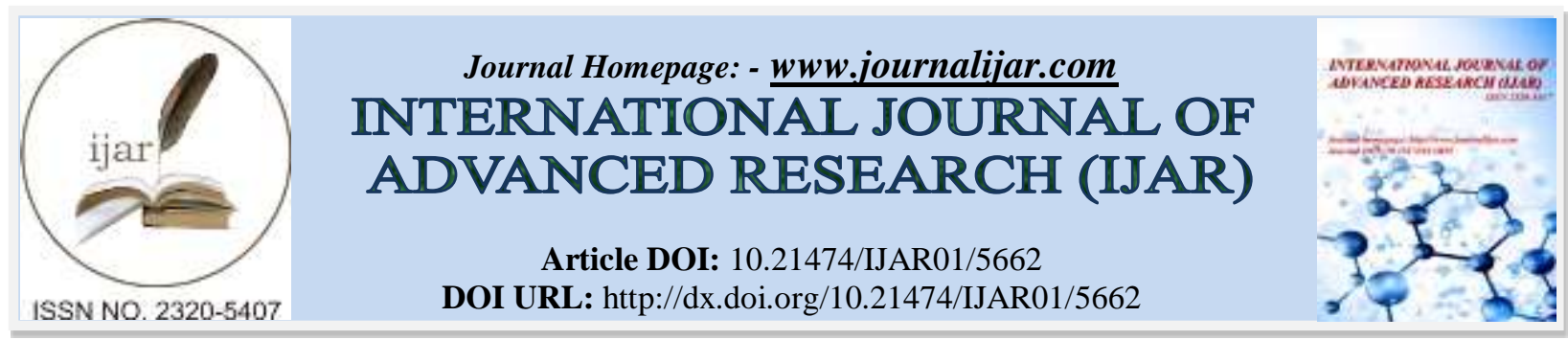

RESEARCH ARTICLE

\title{
JUSTIFICATION, EXCUSE AND EXPLANATION: A PRAGMATIC PERSPECTIVE.
}

Prof. Hameed Hassoon and Mariam D. Saffah.

University of Babylon, College of Education- Human Sciences, Dept. of English

\section{Manuscript Info}

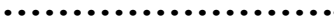

Manuscript History

Received: 19 August 2017

Final Accepted: 21 September 2017

Published: October 2017

\section{Abstract}

Justification and excuse are interrelated speech acts which have much in common in the sense that their purposes often interfere and that only contextual clues make it possible to distinguish one from the other. Nevertheless, in justification, the speaker acknowledges that an offence has occurred and accepts some accountability for it, whereas in excuse, he does not deny his partaking in the offence, but free himself from the responsibility by mentioning external elements without which the offence would not have taken place.

Additionally, justification bears a close resemblance to the speech act of explanation to the extent that it is termed as explanation's close cousin. The latter's function is to make clear or tell why a state of affairs exists. The present paper attempts to investigate the relationship between these three acts detecting their similarities and enhancing their differences.

Copy Right, IJAR, 2017,. All rights reserved.

\section{Introduction:-}

Generally speaking, and according to Hornby (2010: 843), justification means the giving of an explanation or excuse for something or for doing something. For example:

The Prime Minster has been asked to justify the decision to Parliament.

It can inferred from the definition above that there is a close connection between justification, excuse and explanation. That is, both excuse and explanation are used as means of justifying actions or activities.

When employing a justification, the speaker admits that an offence has been committed and accepts some responsibility for it. Simultaneously, he or she supplies mitigating circumstances locating their offensive conduct in a better light and rendering it more acceptable. Justifications are often introduced by the conjunction but, signifying that the speaker admits responsibility, but had a good reason for acting the way he/she did (Ogiermann, 2009: 142)

Because I looked at your case individually and I decided you needed double the dosage.

I simply did not notice you.

Goetz (2010: 403) states that in negotiating the social world, adults often make verbal justifications for their actions or thoughts while making inferences about the feelings and beliefs of others. One can make a claim such as I didn't eat the last cookie, but one is more likely to persuade one's interlocutor if one says, I didn't eat the last cookie because I haven't been in the kitchen. 


\section{The Speech Act of Justification:-}

According to Comparini (2013: 60), justifications are socially and culturally situated speech acts. They are a pragmatic device utilized at certain interpersonal junctures to accomplish certain interpersonal goals.

Prior to that ,Van Dijk (1977a: 202) states that justification is an auxiliary speech act. By an auxiliary speech act is meant an act of which the result is intended as sufficient condition for the successfulness of a main act. A composite act of which some acts are auxiliary acts, is called a complex act. For example:

\section{I'm hungry. Do you have a sandwich for me?}

Here, the speaker does not merely want to state that he is hungry, nor that he is hungry and that he wants a sandwich. Rather, the statement expresses a motivation or reason for making the request as a next speech act. Specifying a justification for the request will make it more acceptable. In certain contexts, such a motivational speech act seems to be required otherwise the hearer would have insufficient information to comply with the request (Van Dijk, 1977b: 102).

As for justification, the intended effect is that of elucidating the reason for doing the main act so as to increase the chances of its success. This is based on the assumption that the hearer is more probable to cope with, for example, a request if he distinguishes and approves of the reason for the request, or to obey an order when it is legitimized by a satisfactory motivation (Ferrara, 1980: 245) .

Edmondson (1981: 147) proposes certain felicity conditions to be satisfied by an utterance in order to be regarded as a speech act of justification. These are:

1. S wishes $\mathrm{H}$ to know that $\mathrm{S}$ does not find a past action $\mathrm{A}$, for which he is fully responsible, socially discreditable.

2. That $\mathrm{S}$ did A, and that this may be deemed socially discreditable is presupposed in the justify. $\mathrm{S}$ is to be interpreted as making a claim as to his own social standing in producing a Justify.

3. There is a complementary relationship between justifications and Excuses as concerns the answerability of the speaker, and whether or not there is, as it were, anything to answer.

According to Goethals (2010: 2208), justification does not primarily focus on the relation between the speaker and the addressee, or that between the speaker and the propositional content, but on the relation between one speech act and the preceding or the succeeding one, as in: That's impossible to know, because/for surely nobody will remember how exactly he was dressed.

Here, the speaker first produces a claim which can be regarded as the main speech act, then he also issues a claim but this time the speech act is intended to justify what has been said before (ibid).

\section{Speech Act Sequences:-}

Ferrara (1980: 234) proposes that speech acts do not usually occur in isolation in real life, rather they come in sequences and are performed by speakers who are engaged in rule-governed activities, such as debating, making conversation, proposing bills in parliament, testifying at trails, teaching in classrooms, preaching and praying in churches, and writing novels. Moreover, speech acts in sequences are normally related to one another, while sharing a different status in the flow of the speaker's action. For instance

\section{There are 30 people in here. Could you open the window?}

Ferrara (ibid: 235) suggests that this pair of utterances could be said in a crowded classroom, in the course of a seminar by someone adjacent to someone else sitting by the window. Here, the speaker's primary goal is to get the window open, whereas the secondary goal is to supply a good justification for the request. He attempts to fulfill the former via addressing an indirect request to the hearer, and the latter by claiming a specific state of affairs to be a good reason for producing the request.

Fraser (1980.: 346) mentions that a very common indirect method of mitigating a directive is by providing as part of the utterance a justification regarding why the hearer should be executing an activity. For instance, one can justify asking someone to close the door by saying, I need the door closed now, or by saying If the door could be closed we could begin. These two alternatives do not have the same degree of mitigation in a certain context, but they both resort to justification of some sort. Additionally, each signifies an attempt by the speaker to make the request more appropriate for the hearer. 
It can be inferred that an assertion is able to create a justificatory relation with the main act as its propositional content depicts a state of affairs which can result in a preferable attitude towards an aim fulfilled by means of numerous set of acts which comprises the justified speech act. Nevertheless, other speech acts are capable of doing so but in another way. For instance, a promise may justify a question (Ferrara: 243):

I will give you a new sweater for Christmas. What's your size?

\section{The Speech Act of Excuse:-}

In Bach and Harnish's terminology, excuse belongs to the category of directives. These convey the speaker's attitude concerning a certain potential action by the hearer. Additionally, they express the speaker's intention that his utterance or the attitude it conveys be regarded as a real reason for the hearer to act.

Edmondson (1981: 147) suggests the following conditions should be satisfied by an utterance to be considered as an excuse.

1. $\mathrm{S}$ wishes $\mathrm{H}$ to believe that $\mathrm{S}$ is not fully accountable for the fact that he performed a past action $\mathrm{A}$, nor is he fully responsible for any consequences following that action.

2. To perform an Excuse is to presuppose that $\mathrm{S}$ did $\mathrm{A}$, and that this may be deemed socially discreditable. $\mathrm{S}$ is therefore to be interpreted as making a plea as to his own standing as a social member in performing an Excuse.

3. An Excuse and Justify share some characteristics.

Furthermore, and according to Ogiermann (2009: 141), when using excuses, offenders do not renounce their involvement in the offence, but name external factors without which the offence would not have occurred, and thereby almost entirely free themselves from the accountability for the offensive consequence.

\section{But there doesn't seem to be anywhere else.}

I thought perhaps you ' $d$ gone for a long time.

In the examples below, selecting the passive voice enables the speaker to shift responsibility for the offence to another party without having to name it.

I was distracted.

I just got robbed.

\section{Justification and Excuse:-}

It may seem difficult task to say what exactly distinguish excuses from justifications. Nevertheless, Austin (1956: 2) believes that justification and excuse both occur in a situation where someone is accused of having done something which is "bad, wrong, inept, unwelcome, or in some other of the numerous possible way untoward." Thus, he will attempt to defend his conduct. There are two options available to do so. The first choice is to admit that he did do that very thing, but to argue that it was a good or an acceptable thing to do. This means that he justifies the action giving reasons for doing it. The other possibility is to admit that it was not a good thing to do, but to argue that it is quit unfair or correct to say badly X did A.

According to Scott and Lyman (1968: 47), justifications are accounts in which one accepts responsibility for the act in question, but denies the pejorative quality connected with it. Hence, a soldier in a battle may confess that he has killed other men, but deny that he did an immoral act as those he murdered were members of an enemy group. However, excuses are accounts in which one admits that the act in question is bad, wrong, or inappropriate but denies full responsibility. Thus, the same solider could acknowledge the wrongfulness of murdering others but claim that his acts are performed unwillingly, i. e., he is under orders and has to obey.

Ogiermann (2009: 138) suggests that the term justification is used to refer to mitigating circumstances justifying not so much the offence itself via redefining it as non-offensive as the offender's behavior leading up to the offence, whereas the term excuse refers to external mitigating circumstances which are obviously beyond the speaker's control and would have led to the offence without their contribution. Consider the examples:

My watch has stopped. (Excuse)

I was suddenly called to a meeting. (Justification)

According to Edmondson (1981: 147), justifications and excuses are not mutually exclusive modes of illocutionary behavior, and it may be expected that some utterances falling within this domain may be indeterminate between the one category or the other. 


\section{Speech Act of Explanation:-}

In Searle's terminology (1979: 12) explain belongs to the category of assertives whose purpose is to commit the speaker to the truth of the conveyed proposition.

According to Van Dijk (1980: 182), explanation is another relation that occurs between speech acts in speech act sequences. For instance:

\section{I have no watch. Can you please tell me the time? (Justification) Can you please tell me the time? I have no watch. (Explanation)}

It can be assumed that the contextual conditions for the second sequence are identical with those of the first. The difference stems from the fact that the assertion no longer establishes the correct context for the request but rather subsequently provides the grounds for the request Therefore, it functions as an explanation of the request. Thus, assertions about conditions of any type that are placed after other speech acts typically have an explanatory function (ibid:183):

\section{Oh, sorry! I didn't see you.}

Walton (2005: 197) proposes that when considered as a speech act, an explanation has to be taken as replay to a preceding question in an exchange. It can be assumed that the asking of the question constitutes the preparatory condition for the speech act in question. Regardless of the kind of the question, the explanation given in response to it should satisfy the pragmatic requirements proper for the conversational context in which the explanation occurs. In a Searlian fashion, Walton (2007b: 7) proposes felicity conditions for the speech act of explaining. These are cited below:

Propositional content condition:

Event, fact, or act A contained in question of $\mathrm{H}$.

Preparatory Condition:

$\mathrm{H}$ is unable to understand $\mathrm{A}$. $\mathrm{H}$ believes that $\mathrm{S}$ can say something that will lead $\mathrm{H}$ to come to understand $\mathrm{A}$.

Sincerity Condition:

$\mathrm{S}$ believes $\mathrm{H}$ understanding A will benefit $\mathrm{H}$.

Essential Condition:

It counts as an attempt to lead $\mathrm{H}$ to understand $\mathrm{A}$.

\section{Justification and Explanation:-}

It has been stated that justification is explanation's close cousin. In this regard, Kasachkoff (1988: 20-9) mentions that justification and explanation serve different purposes. That is, Whereas justifications are offered to convince others of the truth of claims, explanations are given when one desires to make a state of affairs or occurrence clear.

Nevertheless, their purposes are recurrently mingled to the extent that they cannot be separated one from the other. Additionally, it is demonstrated that determining whether a give discourse is an explanation or justification is not always an easy task to do and only the context in which it occurs will decide that (ibid).

Al- Hindawi (1999: 33) states that in his account, Ferrara (1980) concentrates on sequences with a subordinate act plus main act (Justification) avoiding the reference to sequences with a main act plus subordinate act structure (explanation).

Al- Hindawi (ibid.) says that the two types of sequences share some properties. The ingredients of the main act plus subordinate act sequence do not have equal status, i. e., one of them is subordinate to the other. The subordinate act enters into a successfully justificatory relation with the main act. In addition, the main act can be performed to achieve the illocutionary goal without providing further justification for that act. The only difference between the two types of sequences is that in the first type, the subordinate act justifies the performance of the following act, whereas in the second type it justifies the initiation of the preceding act. 
Vandepitte (1993) cited in Henckemans ( 2001: 242) suggests that the choice of conjunctionals such as because, as and since depends on what the speaker assumes the listener already knows. Relations whose cause or reason is presumed to be known by the listener are usually introduced by means of as or since. However, because is rarely used to introduce a manifested state of affairs. Hence, relations marked by as or since are more likely to be part of a justification rather than an explanation.

According to Van Eemeren et al. (2002: 43), the presence of a particular indicator is not sufficient to signal something as a justification. Particularly dangerous are because utterances in the sense that they usually present causes rather than reasons. Instead of being justifications, such utterances function to explain, elaborate, or clarify, as in:

\section{The pudding didn't stiffen because I didn't put enough gelatin in it}

It is proposed that a significant feature of explanation is that whatever is being explained is something that is already approved of. However, the matter is very different with justifications which are usually put forward to bear on a stand point that has not yet been accepted. It is suggested that when in doubt, it is preferable to be careful and to consider the explanation as a justification (ibid).

Sinnott-Armstrong and Fogeline (2015: 4-7) mention that whereas justifications present reasons on behalf of disputed claim, explanations answer questions regarding how or why something happened. The purpose of explanations is not only to demonstrate that something happened, but to make sense of things.

According to Hoaglund (1986: 391), the common feature that most explanations share is that they lack a conclusion, which reasons, evidence, or premises are produced in order to support. The only exception is the explanations that are justifications because they are put forward to justify a situation. For instance, when a teenage child inquires why she is unable to go out, her parent replies that it is due to the fact that she has homework to do.

The child's request for an explanation signifies a hedged demand for a reason regarding confining her. The demand is hedged because personal relations operate more easily when people are requested to explain rather than to justify their demands. Therefore, such justificatory explanations are best considered as arguments because their justifying function takes priority over their explanatory one (ibid: 394).

However, in the example below, it is not clear whether B's replay is a justification or an explanation (Walton, 1996:65):

\section{A: What are you doing that for?}

B: Everybody's doing it.

\section{The Basic Theory of Speech Acts:-}

In the sets of lectures that were posthumously published as How to do Things with Words, Austin revolts against the view of language that placed the truth-conditions as central to language understanding (Levinson, 1983: 228).

Mey (2001: 92) suggests that Austin's book had a great influence on linguistic philosophy, and thereby on linguistics, particularly in its pragmatic variant. Austin's thinking was further developed by his student, the American philosopher John R. Searle who became the main advocate and defender of the former's ideas.

In his own search for ways of coping with language as a sort of action, Austin first made a distinction between constative and performative utterances. In this dichotomy, constatives, such as We went down to Como, are utterances in which something is said which can be evaluated a long a dimension of truth. Performatives, on the other hand, are utterances, such as I promise to go to Como, in which something is done which can be evaluated a long a dimension of falsehood (Verschueren, 1999: 22).

The fact that the constatives-performative distinction are proven to be problematic made Austin modify his initial opinion. Hence, instead of claiming two classes of utterances, Austin asserts that in saying anything one is performing some kind of act (Coulthard, 1985: 17).

According to Levinson(1983: 236), Austin isolates three basic senses in which in saying something one is doing something. Therefore, three kinds of acts are simultaneously performed. 
So, whenever we produce an utterance, we are engaged in three acts. A locutionary act is the production of a well formed utterance in any language one is speaking. The illocutionary act is the meaning we intend to convey. The perlocutionay act is the effects of our words. For instance, when saying, Please open the door, and the listener does so, the speaker has achieved his perlocutionary aim (Black, 2006: 17).

Verschueren (1999: 23) states that Searle systematized Austin's intuitions about felicity by means of a proposal that an appropriate definition of every type of speech act requires four kinds of conditions, all necessary and together sufficient, to be specified.

\section{Classifications of Speech Acts:-}

Austin (1962: 150-160) classifies performative utterances into five general classes which he states that he is far from being satisfied about all of them.

\section{Verdictives:}

Are characterized by the giving of a verdict by a jury, arbitrator, or umpire. However, they need not be final; they may be an estimate, reckoning, or appraisal.

\section{Exercitives:}

Are the exercising of powers, rights, or influence. They comprise appointing, voting, ordering, urging, advising, etc.

\section{Commissives:}

commit $\mathrm{S}$ to a certain course of action. They include promise, covenant, intend, etc.

\section{Expositives:}

Are used in acts of exposition involving the expounding of views, the conducting of arguments, and the clarifying of usages and references. Austin give many examples among them state, affirm, deny, emphasize.

\section{Behabitives:}

Include the notion of reaction to other people's behavior and fortunes and of attitudes and expressions of attitudes to someone else's past conduct or imminent conduct. Austin gives examples such as apologizing, congratulating, cursing, and challenging.

Searle (1979: 11) proposes an alternative taxonomy of speech acts which is founded on the base of three dimensions: illocutionary point, direction of fit, and sincerity condition.

\section{Representatives:}

The point or purpose of the members of the representative class is to commit the speaker to something's being the case, to the truth of the expressed proposition.

\section{Directives:}

The illocutionary point of these consists in the fact that they are attempts by the speaker to get the hearer to do something.

\section{Commissives:}

Commissives are those illocutionary acts whose point is to commit the speaker to some future course of action.

Expressives:- The illocutionary point of this class is to express the psychological state specified in the sincerity condition about a state of affairs specified in the propositional content.

Declarations:- It is the defining characteristic of this class that the successful performance of one of its members brings about the correspondence between the propositional content and reality. Successful performance guarantees that the propositional content corresponds to the world. 


\section{Conclusions:-}

On the basis of the discussion conducted throughout this study, it can be concluded that:

1. Justification, excuse and explanation are three communicative acts which occur as part of an utterance that consists of a sequence of speech acts produced by the same or different speakers. Their basic function is to justify or to explain why the hearer performs a certain act or commits an offence.

2. It has been found out that justification and excuse both occur in a situation in which someone has been accused of having committed an offence. However, in justification, the speaker admits that he has committed an offence but argues that it is an acceptable thing to do. That is, he gives reasons for committing that offence. In excuse, on the other hand, he acknowledges that it is not a good thing to do but argues it is unfair or incorrect to say that he committed that offence.

Put differently, whereas in the former, the speaker acknowledges that an offence has taken place and provides reasons to make that offence look more acceptable, in the latter, the speaker tries to free himself from responsibility for the offence by referring to some external factor lies beyond his control. This is manifested in the following examples:

I was suddenly called to a meeting. (Justification)

My watch has stopped. (Excuse)

3. Justification and explanation both refer to relationships between speech acts in speech act sequences. However, in the former, assertions about conditions of any type are positioned before the main act, while in the later, these are placed after the main act, for example:

I am hungry. Do you have a sandwich for me? (justification)

Stop worrying. He isn't dangerous.( Explanation)

4. Moreover, a salient feature of explanation is that whatever is being explained is something that has already been approved of. Nevertheless, justifications are typically produced to bear on a stand point that has not yet been accepted.

5. Furthermore, although causal connectives such as because, as and since cannot be used as means of identifying justifications, there is a strong tendency to interpret causal relations marked by as and since to be part of justifications rather than explanations.

\section{References:-}

1. Austin, J. L. (1956). A Plea for Excuse. The Presidential Address. The Aristotelian Society, Vol. 57, pp. 1-30.

$2 . \quad$. (1962) How To Do Things With Words. Oxford: Clarendon Press.

3. Al- Hindawi, F. (1999). Iraqi EFL Learners' Use of the Speech Acts of Command and Request. Unpublished $\mathrm{Ph}$. D. Dissertation. University of Baghdad.

4. Bach, K. and Harnish, R. (1978). Linguistic Communication and Speech Acts. Cambridge: The MIT Press.

5. Black, E. (2006) Pragmatic Stylistics. Edinburgh: Edinburgh University Press.

6. Comparini, L. (2013). The Use of Justification in the Linguistic Construction of Agency and Social Connection in Latina Mother-Child Conflict. Journal of Pragmatics, 57, 57-67.

7. Coulthard, Malcolm (1985). An Introduction to Discourse Analysis. London : Longman

8. Edmondson, Willis (1981). Spoken discourse : A Model for Analysis. London: Longman.

9. Ferrara, A. (1980). An extended theory of speech acts: appropriateness conditions for subordinate acts in sequence. Journal of Pragmatics (4). 233 - 252 .

10. Fraser, B. (1980). Conversational Mitigation. Journal of Pragmatics, 4, 341-350

11. Goethals, Patrick. (2010). A Multi-Layered Approach to Speech Event: The Case of Spanish Justificational Conjunctions. Journal of Pragmatics, 42, 2204-2218.

12. Goetz, P. J. (2010). The Development of Verbal Justifications in the Conversations of Preschool Children and Adults. First Language, (30), (3), 403-420.

13. Henkemans, F. (2001). Argumentation, Explanation and Causality: An Explanation of Current Linguistic Approaches to Textual relations. In Sanders, T., Schilperoord, J. and Spooren, W. (Eds.) Text Representation: Linguistic and Psycholinguistic Aspects. Amsterdam: John Benjamins Publishing Company.

14. Hornby, A. S. (2010) Oxford Advanced Learner's Dictionary. Oxford: Oxford University Press.

15. Houglund, J. (1986). Arguments and Explanations. In Van Eemeren, F., Grootendorst, R., Blair, J. and Williard, C. (Eds.) Argumentation: Across the Line of Discipline. Dordrecht: Foris Publication.

16. Kasachkoff, T. (1988). Explaining and Justifying. Informal Logic, 1, 21-30.

17. Levinson, S. (1983). Pragmatics. Cambridge: Cambridge University Press.

18. Mey, Jacob (2001). Pragmatics: An Introduction. Oxford: Blackwell . 
19. Ogiermann, E. (2009). On Apologizing in Negative and Positive Politeness Cultures. Amsterdam: John Benjamins Publishing Company.

20. Scott, M. and Layman, M. (1968) Accounts. American Sociological Review, Vol. 33, No. 1, 46-62.

21. Searle, J. (1979). Expression and Meaning. Cambridge: Cambridge University Press.

22. Sinnott-Armstrong, W. and Fogelin, R. (2015). Understanding Argument an Introduction to Informal Logic. Stamford: Cengage Learning.

23. Van Dijk, Teun A. (1977a) Text and Context. London: Longman.

24.

(1977b). Pragmatic Macrostructures in Discourse and Cognition. University of Amsterdam, 99-113.

25. (1980) Macrostructures: An Interdisciplinary Study of Global Structures in Discourse, Interaction, and Cognition. New Jersey: Lawrence Erlbaum Associates.

26. Van Eemeren, F., Grootendorst, R. and Henkemans, F. (2002). Argumentation, Evaluation, Presentation. New Jersey: Lawrence Erlbaum Associates, Inc.

27. Verschueren, Jef (1999). Understanding Pragmatics. London: Arnold.

28. Walton, D. (1996). Argument Structure: A Pragmatic Theory. Toronto: University of Toronto Press.

29. (2005). Argumentation Methods for Artificial Intelligence in Law. Berlin: Springer.

30. (2007a). The Speech Act of Clarification in a Dialogue Model. Studies in Communication Sciences, 7, 2, 165-197.

31. (2007b). Dialogical Models of Explanation. Papers from the AAAI Workshop, Association for the Advancement of Artificial Intelligence, Technical Report, AAAI Press, 1-9. 